\title{
Worst Imaginable Pain
}

National Cancer Institute

\section{Source}

National Cancer Institute. Worst Imaginable Pain. NCI Thesaurus. Code C103511.

The most severe pain an individual can conceive of experiencing. 